\title{
Clinical Trials for Preterm Infants' Neurodevelopment to the Norm: Erythropoietin and Nutritional Interventions
}

Sook-Hyun Park, M.D.

Department of Pediatrics, Kyungpook National University School of Medicine, Daegu, Korea

\section{ABSTRACT}

Although the incidence of severe intraventicular hemorrhage and cystic periventricular leukomalacia in preterm infants has significantly decreased, approximately $10-15 \%$ of preterm survivors demonstrate cerebral palsy and $50-80 \%$ of extremely preterm infants demonstrate mild-to-severe neurodevelopmental impairment. Compared to term infants, preterm infants show a higher incidence of brain damage secondary to hypoxic injury, inflammation, and malnutrition. Clinical trials have evaluated outcomes following early administration of high dose erythropoietin and nutritional interventions including early aggressive nutrition, human breast milk, and long-chain polyunsaturated fatty acids supplementation to prevent preterm infants' neurodevelopmental impairment and improve neurodevelopmental outcome. Further studies are warranted to investigate the safety, optimal dose, timing, duration with respect to erythropoietin and nutritional interventions, and the optimization of a target population of preterm infants suited for interventions.

Key Words: Erythropoietin, Nutrition, Long-chain polyunsaturated fatty acids, Preterm infants

서론

최근 미숙아의 중증 뇌실내 출혈, 낭포성 백질 연화증 등의 신경학적 후유증이 현저하게 감소 하였음에 불구하고 여전히 10-15\%의 미숙아에서 뇌성 마비 또는 심한 강직성 운동 장애 등을 보 이는 영구적인 운동 신경 손상을 보인다 ${ }^{1,2)}$. 특히 재태주령 26주 미만 출생한 미숙아는 생후 30 개 월에는 $50 \%, 6$ 세에는 $80 \%$ 에서 경증 또는 중등도의 신경발달학적 장애가 나타난다,34)

태아기 동안 뇌 발달은 임신 2 분기에는 신경 세포의 생성과 이동이 나타나고 시냅스의 생성이 시작된다. 별아교세포와 희소돌기아교세포의 발달도 이에 뒤따르게 된다 ${ }^{1)}$. 임신 3 분기에는 뇌 용적의 증가와 모양의 정교함이 급격하게 이루어지는 시기이며,(5), 특히 재태 주령 24 주에서 32 주 사이에는 희소돌기아교세포가 발달과 성숙이 이루어지는 시기로 흥분성 신경 독성, 저산소화 및 산소 독성에 가장 취약한 기간이다 ${ }^{7,8)}$. 미숙아의 뇌손상은 희소돌기아교세포의 취약성에 의한 백질 손상뿐만 아니라 수상돌기세포 형성 이상을 초래하여 백질 뿐만 아니라 회백질의 용적 감 소 소견을 보이기도 한다 ${ }^{9,10)}$.
Received: 23 July 2017

Accepted: 1 August 2017

Correspondence to: Sook-Hyun

Park

Department of Pediatrics, Kyungpook National University School of Medicine, 90 Chilgokjungang 130-ro, Buk-gu, Daegu 41405, Korea

Tel: +82-53-200-2812

Fax: +82-53-425-6683

E-mail: park_sh@knu.ac.kr

Copyright(c)

By Korean Society of Neonatology.

All right reserved.

This is an Open-Access article distributed under the terms of the Creative Commons Attribution Non-Commercial License (http://creativecommons.org/licenses/ by-nc/4.0), which permits unrestricted non-commercial use, distribution, and reproduction in any medium, provided the original work is properly cited. 
미숙아는 뇌신경 발달이 급속하게 이루어지는 시기에 출생하게 됨으로써 이른 출생 자체만으로도 정상적인 두뇌 발달 과정에 변화 를 초래하여 뇌 용적의 감소를 동반하는데 이는 불량한 신경발달학 적 예후와 관련된다고 알려져 있당․ 뿐만 아니라 출생과 동시에 저 산소 허혈성 또는 과산소화에 의한 스트레스, 염증반응 등 뇌손상 을 유발할 수 있는 여러가지 요인에 노출된다 ${ }^{11}$. 출생 전후에 나타나 는 융모양막염, 괴사성 장염, 패혈증 등과 같은 급성과 만성 염증에 서 염증반응에 관여하는 Tumor necrosis factor- $\alpha$, interleukin (IL)-6, IL-8은 뇌 산소화 대사에 관여하여 미숙아의 뇌손상과 관련성이 있다 고 알려져 있다 ${ }^{12,13)}$. 앞서 언급한 원인들에 의해 손상받은 미숙아의 뇌는 뇌손상의 빈도가 증가하고 백질과 회백질의 용적 감소, 신경세 포 활성화의 변화, 신경세포 연결의 구조적 변화 및 뇌겉질밑층의 변 화를 초래한다 ${ }^{14-16)}$.

현재까지 이러한 미숙아의 신경발달학적 손상을 최소화하여 정상 적인 발달에 근접하기 위한 약물학적, 영양학적인 임상적인 시도들 이 지속되고 있다. 저자는 미숙아의 신경을 보호하고 뇌 손상을 방 지하기 위한 erythropoietin (Epo)과 영양학적 중재, 특히 long-chain polyunsaturated fatty acids (LCPUFAs)의 임상적 적용에 대한 최신 연구들을 확인하고자 한다.

\section{신경보호 작용으로서 Erythropoietin의 임상적 적용}

\section{Erythropoietin의 작용 기전}

Epo의 주된 역할은 적혈구 생성을 담당하며, 출생 전에는 간에서 주로 만들어지고 출생 이후에는 신장에서 생산이 이루어진다. 저산 소증, 주로 장시간의 조직 저산소화에 의하여 $\mathrm{Epo}$ 는 별아교세포, 희 소돌기아교세포, 신경 세포 및 미세아교세포와 같은 뇌세포에서 생 산이 증가되고 이는 중추신경계의 성장과 신경 보호 작용에서 중요 한 역할을 가진다 ${ }^{1,17,18)}$. 이러한 기전을 바탕으로 뇌혈관장벽의 통과 가 가능한 human recombinant Epo의 투여를 통한 뇌신경보호에 대 한 연구가 이루어지고 있다.

저산소화와 허혈성 자극은 Epo의 생성을 자극하는 가장 중요한 요인으로, Epo는 허혈성 환경에서 glutamate의 독성의 감수성을 감 소시키고 신경세포에서 항산화 작용을 증가시킨다 ${ }^{19)}$. Epo는 항염증 작용을 가지고 있어 급성, 만성 염증 상태에 의한 뇌손상을 보호하는 역할을 하며 ${ }^{20}$, 또한 Epo는 신생 혈관을 증식시킴으로써 허혈이 일 어난 조직으로 혈류량과 산소화를 증가시킨다 ${ }^{21)}$. 적혈구 생성을 통 해서 잠재적으로 신경 손상을 초래할 수 있는 자유 산화기인 결합하 지 않은 철분을 소모하는 역할도 한다 ${ }^{22)}$. 이러한 Epo의 작용이 희소 돌기아교세포의 생성을 촉진함으로써 저산소 허혈에 의한 백질 뇌 손상에서 신경 세포 발생을 증가시킨다 ${ }^{23)}$.
Epo의 신경 보호 기전은 뇌손상의 급성기 동안에는 항세포자멸, 항염증, 그리고 항산화 작용으로 신경 세포를 보호하는 역할을 하고 회복기 동안에는 신경 발생을 가속화시키고 신생 혈관의 증식을 통 해서 뇌 발달과 치유의 역할을 담당하게 된다 ${ }^{12,24}$. 동물 실험에서는 손상 받은 매우 미성숙한 뇌를 가진 쥐에게 $\mathrm{EpO}$ 를 투여한 후에 뇌백 질 용적의 증가에 관계 없이 뇌백질의 미세 조직과 신경계의 기능적 연결성의 향상뿐만 아니라, 체성감각을 담당하는 겉질 기능을 회복 시키는 결과를 보였다 ${ }^{25}$.

\section{2. 미숙아에 적용된 Erythropoietin 의 신경 보호 작용으로서 임상적 적용}

고용량의 $\mathrm{Epo}$ 를 미숙아에게 투여하는 약물의 안정성에 대한 연 구들이 진행되었다. Juul 등 ${ }^{26)}$ 은 재태 주령 29주 미만의 초극소저체 중출생아(Extremely Low birth Weight Infants, ELBWIs)를 대상으 로 출생 첫 날 24시간 간격으로 각각 $500,1,000$, 또는 $2,500 \mathrm{IU} / \mathrm{kg}$ 를 3 차례 투여하였다. 평균 동맥압, 미숙아 망막증, 괴사성 장염, 뇌실 내 출혈, 패혈증의 발생 빈도와 생존률은 대조군과 차이가 없었고 투 여한 Epo 용량에 따른 차이도 보이지 않았다. Fauchere 등 ${ }^{27,28)}$ 은 재 태 주령 24 주에서 32 주 미만의 미숙아를 대상으로 출생 후 3 시간이 내, 12-18시간, 36-42시간에 3차례 Epo 3,000 IU/kg 를 투여하고 생 리 식염수를 투여한 군과 비교하였는데 혈압, 뇌 산소화 정도, 그리 고 혈색소, 백혈구, 적혈구 수치에서 의미 있는 차이를 보이지 않았 고 미숙아의 사망률과 뇌실내 출혈, 미숙아 망막증, 패혈증, 괴사성 장염, 기관지폐 이형성증의 발생 빈도의 차이도 없었다.

출생 초기 고용량의 Epo 투여가 미숙아의 단기 또는 장기적 신 경발달학적 예후에 미치는 영향에 대한 여러 연구들이 이루어졌다 (Table 1). Bierer 등 ${ }^{29}$ 은 미숙아에서 출생 초기 Epo 투여에 따른 혈 중 Epo 농도가 교정 연령 18-22개월의 발달에 미치는 영향에 대해 확인하였다. 혈중 Epo 농도는 Psychomotor Developmental Index (PDI)와는 관련성을 보이지 않았으나 최고 혈중 Epo 농도가 500 $\mathrm{mU} / \mathrm{mL}$ 보다 높은 미숙아에서 높은 Mental Developmental Index (MDI)를 가지는 것으로 나타났다. Song 등 ${ }^{30}$ 은 재태주령 32주 미만 미숙아를 대상으로 Epo $500 \mathrm{IU} / \mathrm{kg}$ 를 생후 72시간 내에 시작하여 2 주 동안 격일에 한 번 투여 하였고 교정 연령 18 개월에 Bayley scales of infant development (BSID)-II을 시행하였다. 사망과 심각한 신경 학적 장애의 발생 빈도는 Epo를 투여한 미숙아에서 대조군에 비하 여 낮았는데, 뇌백질 연화증과 grade III 이상의 뇌실내 출혈의 빈도 가 낮게 확인 되었다. 또한, 미숙아망막증의 발병 빈도는 두 군간에 차이를 보이지 않았다. Natalucci 등 ${ }^{31}$ 은 재태 주령 24 주에서 32 주 미 만의 미숙아를 대상으로 출생 후 3시간이내, 12-18시간, 36-42시간 에 3차례 Epo 3,000 IU/kg 를 투여하고 생리 식염수를 투여한 미숙아 와 교정 연령 2세에 BSID-II, 뇌성 마비, 청력과 시력 손상의 발생 빈 도를 비교하였다. Epo를 투여한 미숙아에서 BSID-II의 MDI와 PDI가 
Table 1. Clinical Trials of Early Prophylactic High-Dose Erythropoietin for Neuroprotection in Preterm Infants

\begin{tabular}{|c|c|c|c|c|}
\hline Author/year & Population & Intervention & Outcome measures & Results \\
\hline $\begin{array}{l}\text { Bierer RB, et al. } \\
2006^{29)}\end{array}$ & $\begin{array}{l}401 \text { to } 1,000 \mathrm{~g}, \\
\text { GA } \leq 32 \text { weeks }\end{array}$ & $\begin{array}{l}\text { rhEpo } 400 \mathrm{IU} / \mathrm{kg} 3 \text { time } \\
\text { weekly until discharge }\end{array}$ & $\begin{array}{l}\text { BSID-II at } 18 \text { to } 22 \\
\text { months' CA }\end{array}$ & $\begin{array}{l}\text { rhEpo ( } n=6) \text { vs. placebo }(n=6) \\
\text { MDI <70: rhEpo (0/6) vs. placebo }(2 / 6) \\
\text { PDI <70: rhEpo }(2 / 6) \text { vs. placebo }(2 / 6)\end{array}$ \\
\hline $\begin{array}{l}\text { Song J, et al. } \\
2016^{30)}\end{array}$ & $\mathrm{GA} \leq 32$ weeks & $\begin{array}{l}\text { rhEpo } 500 \mathrm{IU} / \mathrm{kg} \text { within } 72 \\
\text { hours after birth, every } \\
\text { other day for } 2 \text { weeks }\end{array}$ & $\begin{array}{l}\text { BSID-II at } 18 \text { months' } \\
\text { CA }\end{array}$ & $\begin{array}{l}\text { rhEpo }(\mathrm{n}=309) \text { vs. placebo }(\mathrm{n}=304) \\
\text { Death or moderate } / \text { severe neurological disability: } \\
\text { rhEpo }(\mathrm{RR}=0.40,95 \% \mathrm{CI}=0.27-0.59, P<0.001) \\
\text { MDI }<70 \text { : } \operatorname{rhEpo}(\mathrm{RR}=0.33,95 \% \mathrm{CI}=0.19-0.58, P<0.001)\end{array}$ \\
\hline $\begin{array}{l}\text { Natalucci G, et al. } \\
2016^{31)}\end{array}$ & $<1,000 \mathrm{~g}$ & $\begin{array}{l}\text { rhEpo } 400 \mathrm{IU} / \mathrm{kg} 3 \text { times } \\
\text { weekly } \\
\text { From } 96 \text { hours of age to } 35 \\
\text { weeks' PMA }\end{array}$ & $\begin{array}{l}\text { BSID-II (MDI }<70 \\
\text { PDI }<70) \text { at } 18 \text { to } 22 \\
\text { months' CA }\end{array}$ & $\begin{array}{l}\text { rhEpo ( } n=51) \text { vs. placebo }(n=51) \\
\text { MDI <70: rhEpo ( } 34 \%) \text { vs. placebo }(36 \%) \\
\text { Cerebral palsy: rhEpo (16\%) vs placebo }(18 \%)\end{array}$ \\
\hline $\begin{array}{l}\text { Ohls RK, et al. } \\
2016^{32)}\end{array}$ & 500 to $1,250 \mathrm{~g}$ & $\begin{array}{l}\text { rhEpo } 400 \mathrm{IU} / \mathrm{kg} 3 \text { times } \\
\text { weekly, or Darbepoetin } \\
10 \mu \mathrm{g} / \mathrm{kg} \text { once weekly } \\
\text { until } 35 \text { weeks' PMA }\end{array}$ & $\begin{array}{l}\text { WPPSI-III at } 3.5 \text { to } 4 \\
\text { years old }\end{array}$ & $\begin{array}{l}\text { ESA ( } \mathrm{n}=39) \text { vs. placebo }(\mathrm{n}=14) \\
\text { Full-scale IQ: } 91.1 \pm 17.5 \text { vs. } 79.2 \pm 18.5(P=0.036) \\
\text { Verbal IQ: } 91.7 \pm 18.3 \text { vs. } 82.9 \pm 16.9(P=0.036) \\
\text { Performance IQ: } 93.0 \pm 17.0 \text { vs. } 79.5 \pm 19.5(P=0.018)\end{array}$ \\
\hline $\begin{array}{l}\text { Neubauer AP, et al. } \\
2010^{24)}\end{array}$ & $<1,000 \mathrm{~g}$ & rhEpo 1,750-21,500 IU/kg & $\begin{array}{l}\text { HAWIK-III at } 10 \text { to } 13 \\
\text { years old }\end{array}$ & $\begin{array}{l}\text { rhEpo ( } \mathrm{n}=89) \text { vs. placebo }(\mathrm{n}=57) \\
\text { Composite IQ: } 90.8 \pm 17.2 \text { vs. } 81.3 \pm 21.1(P<0.005) \\
\text { Verbal IQ: } 95.7 \pm 16.2 \text { vs. } 88.1 \pm 21.7(P<0.05) \\
\text { Nonverbal IQ: } 86.0 \pm 16.5 \text { vs. } 77.4 \pm 17.9(P<0.005)\end{array}$ \\
\hline
\end{tabular}

Data are presented as mean \pm SD.

Abbreviations: GA, gestational age; rhEpo, recombinant human erythropoietin; BSID, Bayley scales of infant development; CA, corrected age; MDI, mental development index; PDI, psychomotor development index; PMA, postmenstrual age; RR, relative risk; CI, confidence interval; WPPSI, Wechsler preschool and primary scale of intelligence; ESA, erythropoiesis-stimulating agent; IQ, intelligence quotient; HAWIK, Hamburg-Wechsler intelligence test for children.

대조군에 비해서 높지 않았고 뇌성 마비, 시력과 청력 손상의 발생 빈도도 차이를 보이지 않았다.

Ohls 등 ${ }^{32}$ 은 출생 초기 고용량의 $\mathrm{EpO}$ 를 투여한 미숙아를 대상으 로 4세에 인지 기능(Intelligence quotient, IQ)을 평가하였는데 Epo 를 투여한 미숙아에서 투여하지 않은 미숙아에 비해 높은 인지 기 능 점수를 보였고 낮은 빈도의 신경 발달 장애가 나타났다. 앞선 연 구와 같은 미숙아를 대상으로 3.5-4세에 Behavioral Assessment of System for children (BASC-2)로 행동을 평가한 결과, Epo를 투여한 미숙아에서 발달된 행동 양상을 보였다 ${ }^{33)}$. Neubauer 등 ${ }^{24)}$ 은 생후 첫 1주일 동안 Epo를 투여한 ELBWIs 미숙아들을 대상으로 10-13세에 인지 기능(IQ in Hamburg-Wechsler Intelligence Test for ChildrenIII)과 신경 발달 장애의 정도를 평가하였다. Epo를 투여한 미숙아의 인지 기능 점수가 투여하지 않은 미숙아에 비해서 높게 확인되었고 뇌성 마비, IQ 70 미만의 인지 기능 장애, 시력과 청력 장애와 같은 신경 발달 장애의 발생 빈도가 낮게 확인되었으며, 뇌실내 출혈을 동 반하는 경우 이러한 차이는 현저하게 나타났다.

미숙아의 Epo 투여가 뇌의 구조적 혹은 기능적으로 미치는 영향 에 대해 확인하고자 뇌자기공명영상 (Magnetic Resonance Imaging, $\mathrm{MRI}$ )에 대한 연구가 이루어졌다. 재태 주령 26주에서 32주 미만의 미숙아를 대상으로 출생 후 3 시간 이내, 12-18시간, 36-42시간에 3
차례 Epo 3,000 IU/kg 를 투여한 군과 생리 식염수를 투여한 군으 로 나누어 Epo가 뇌에 미치는 영향을 재태 주령 40주에 뇌 MRI와 확 산텐서 영상(Diffusion Tensor Imaging, DTI)으로 확인하였다. Leuchter 등 ${ }^{34}$ 은 뇌 MRI에서 미숙아의 뇌백질과 회백질의 손상 정도를 Woodward system으로 ${ }^{35)}$ 점수화한 결과 Epo를 투여한 미숙아에서 뇌백질, 회백질 손상 정도의 감소를 보였으며, 뇌실 주위 뇌백질 용 적의 감소도 적게 나타났다. O'Gorman 등 ${ }^{36)}$ 은 Epo가 뇌백질의 발 달에 미치는 영향을 DTI로 확인하였는데 Epo를 투여한 미숙아는 생리 식염수를 투여한 군과 비교하여 뇌량, 겉질 척수로, 속 섬유막 (internal capsule)에서 뇌백질의 integrity의 정도를 객관적으로 확인 할 수 있는 fractional anistopy가 의미있게 증가된 양상을 보였다.

재태 주령 24주에서 27주 이하 초극소 미숙아를 대상으로 Epo 400 $\mathrm{IU} / \mathrm{kg}$ 를 출생 24시간 내에 투여를 시작하여 48시간 간격으로 32 주 6 일까지 투여하는 연구(Preterm Epo Neuroprotection Trial, PENUT Trial)와 ${ }^{11)}$ 재태 주령 32 주 미만 또는 출생 체중 $1,500 \mathrm{~g}$ 미만의 grade II-IV 뇌실내 출혈이 있는 미숙아를 대상으로 Epo 2,000 IU $/ \mathrm{kg}$ 를 생 후 3-7일에 시작하여 5차례 투여하여 5세까지 신경발달학적 예후 를 확인하고자 하는 연구(Erythropoietin for the Repair of Cerebral Injury in very preterm infants, EpoRepair trial)가 진행 중이다 ${ }^{37)}$. 


\section{미숙아에서 신경 발달학적 예후의 향상을 위한 영양학적 중재의 임상적 시도}

생후 초반의 뇌 발달에는 독성 스트레스와 감염의 감소, 사회적 지지, 적절한 영양이 가장 중요한 요인으로 알려져 있다 ${ }^{38)}$. 생후 첫 1,000 일 동안이 신경 발달의 예후에 가장 영향을 미치는 시기로 중요 성이 대두되고 있다 ${ }^{39)}$. 재태 주령 32 주부터 생후 2 세까지 뇌 신경 수 초화가 급격하게 증가하는 시기이고 기억과 인지 기능에 관여하는 해마도 재태 주령 32 주부터 생후 18 개월에 걸쳐서 급격한 성장을 보 인다물. 태아기 및 출생 초기에는 이러한 뇌 발달이 급격하게 이루어 지는 시기이므로 영양 결핍에 신경 세포들이 특별히 취약하다 ${ }^{41)}$. 영 양소의 종류, 결핍 또는 과잉의 정도, 시기, 결핍의 기간에 따라서 각 각 다른 신경 세포와 성숙 과정에 관련되어 뇌 발달 및 인지 기능에 영향을 미친다 ${ }^{39,41,42)}$. 미숙아의 생후 초기 이른 충분한 영양 공급은 통한 영양소 결핍의 감소와 적절한 체중 증가는 뇌성 마비의 발생 빈 도를 낮추고 뇌의 성장과 발달, 신경 발달학적 예후를 향상시키는 것 과 관련성이 있다고 알려져 있다 ${ }^{41,43)}$.

\section{1. 조기 고용량의 단백질과 지방의 공급에 따른 미숙아의 신 경발달학적 예후}

미숙아의 조기 정맥 영양과 장관 영양을 통한 충분한 단백질과 지 방의 공급은 청신경과 시신경 발달의 향상을 포함하여 전반적인 신 경 발달학적 예후와 관련 있다 ${ }^{42-44)}$. 특히 초기 단백질 공급량이 뇌 성 장과 발달, 뇌 용적의 증가와 밀접한 상관 관계를 보인다 ${ }^{45-47)}$. Ohni shi 등 ${ }^{48)}$ 은 ELBWIs를 대상으로 출생 초기 단백질 양에 따른 교정 연 령 18개월과 3세의 발달을 Kyoto Scale of Psychological Development (KSPD)을 이용하여 평가 하였다. 생후 첫 날 $1.5-2.0 \mathrm{~g} / \mathrm{kg} / \mathrm{day}$ 의 단백질을 공급하여 $3.5 \mathrm{~g} / \mathrm{kg} / \mathrm{day}$ 로 증량한 미숙아와 생후 4 일째 $0.5 \mathrm{~g} / \mathrm{kg} / \mathrm{day}$ 로 시작하여 $1.0 \mathrm{~g} / \mathrm{kg} / \mathrm{day}$ 를 공급한 미숙아를 비교하 였다. 교정 연령 18 개월, 3 세에 시행한 발달 검사에서 인지-적응 능 력이 고용량의 단백질 공급 받은 미숙아에서 높게 확인되었고 언어사회성, 운동 기능에서는 차이가 없었다. 이 연구에서 3 세의 인지 기 능 발달에 관련되는 요인을 분석한 결과 출생 초기 고용량의 단백질 공급, 출생 체중에 도달하는 기간, 장관 영양(full enteral feeding)이 이루어지는 기간과 관련성을 보였다. Blanco 등 ${ }^{49}$ 은 ELBWIs를 대상 으로 생후 첫 7일 동안 저용량 $(0.5 \mathrm{~g} / \mathrm{kg} / \mathrm{day}$ to $3.0 \mathrm{~g} / \mathrm{kg} / \mathrm{day})$ 과 고용 량 $(2.0 \mathrm{~g} / \mathrm{kg} /$ day to $4.0 \mathrm{~g} / \mathrm{kg} / \mathrm{day})$ 단백질을 공급한 경우로 나누어서 교정 연령 2세에 BSID-II을 시행하였다. 앞선 연구의 결과와는 반대 로 조기에 고용량의 단백질을 공급 받은 미숙아가 저용량의 단백질 을 공급 받은 미숙아와 비교하여 MDI 점수가 의미 있게 낮았고 축척 된 단백질량과 $\mathrm{MDI}$ 점수가 음의 상관 관계를 가졌다. 미숙아에서 조 기 고용량의 단백질과 지방의 공급이 뇌 성장 및 발달에 미치는 영향 을 확인하고자 시행한 뇌 MRI에서 생후 첫 2주 동안 높은 열량과 고
용량의 지방을 공급할 수록 뇌 손상의 빈도가 감소하였고 뇌 성숙 정 도를 향상시켰으며 ${ }^{50)}$, 고용량의 단백질과 지방을 공급할수록 DTI에 서는 뇌 신경 연결의 성숙도가 향상되었다 ${ }^{51}$. 여러 연구 결과, 미숙 아의 적절한 신경 발달을 위해서는 하루에 3-4 g/kg 의 단백질 공급 이 필요하다고 생각 된다 ${ }^{41,52)}$.

\section{2. 모유와 미숙아의 신경발달학적 예후}

모유는 분유에 비하여 뇌 발달을 향상 시킬 수 있는 적합한 영양원 으로 여겨지며 임상적 시도를 통해서 모유 수유가 미숙아의 신경발 달학적 예후의 향상과 관련 있음을 확인할 수 있다 ${ }^{53-55)}$. 모유가 미숙 아의 신경 발달 향상과 관련된 기전에 대해서 완전히 밝혀지지는 않 았지만 Long-chain polyunsaturated fatty acids (LCPUFAs)와 모유의 oligosaccharides가 중요한 요인으로 생각된다 ${ }^{53)}$. LCPUFAs는 인지 기능 향상과 시력 발달과 관련성이 있으며 oligosaccharides는 미숙 아의 장내 세균총을 건강하게 형성하여서 미숙아의 불량한 신경발 달학적 예후와 관련되는 괴사성 장염의 위험성을 낮춤으로써 미숙 아의 신경 발달에 영향을 미친다 ${ }^{53,56,57)}$. Vohr 등 ${ }^{58,59)}$ 은 NICU 입원 기 간 중 ELBWIs가 섭취한 모유량과 발달과의 상관 관계에 대해서 분 석하였다. 교정 연령 18 개월에는 섭취한 모유량이 $10 \mathrm{~mL} / \mathrm{kg} / \mathrm{day}$ 증 가할수록 BSID-II에서 MDI 는 0.53점, $\mathrm{PDI}$ 는 0.63점 증가하였고 재 입원률은 감소하였다. 생후 30 개월에는 섭취하는 모유량이 $10 \mathrm{~mL} /$ $\mathrm{kg} / \mathrm{day}$ 증가할수록 BSID-II에서 MDI 는 0.59점, PDI 는 0.56점 증가 하는 양상을 보였다. 생후 첫 4주동안 모유 수유를 한 미숙아와 분유 수유를 한 미숙아를 5세에 인지 기능을 평가한 결과 모유 수유를 한 미숙아에서 높게 확인되었으며 인지 기능 점수는 생후 4 주에 측정 한 혈중 docosahexaenoic acid (DHA) 농도와 유의한 상관 관계를 보 였다 ${ }^{(0)}$. 또한 모유를 수유한 미숙아들을 대상으로 뇌 MRI를 시행한 결과 모유 수유 비율이 높을수록 뇌백질의 용적과 인지 기능이 높게 나타났고 모유 수유 기간이 길수록 뇌 백질의 발달을 향상시키고 전 두엽과 같이 늦은 시기에 발달이 이루어지는 뇌 부위에서도 발달이 이루어졌다 ${ }^{61,(2)}$. Belfort 등 ${ }^{(3)}$ 은 재태 주령 30 주 미만 또는 출생 체중 $1,250 \mathrm{~g}$ 미만의 미숙아를 대상으로 생후 첫 28일 동안 모유 섭취 비 율이 50\% 가 넘는 기간을 확인하여 재태 주령 40주와 7세에 뇌 MRI 를 시행하였고 7세에 인지 기능을 평가하였다. 모유의 섭취 비율이 $50 \%$ 가 넘는 기간이 길수록 재태 주령 40주에 시행한 뇌 MRI에서 뇌 회백질의 용적이 증가하였고 7 세에 인지 기능, 수학, 기억력과 운동 능력 모두 높게 확인되었다.

\section{Long-Chain Polyunsaturated Fatty Acids의 역할}

LCPUFAs는 뇌와 망막을 구성하는 세포막의 구성 요소로 DHA (22:6n-3)와 arachidonic acid (AA, 20:4n-6)가 중추 신경계와 신경 세 포를 형성하는 주가 되는 필수 지방산이다. LCPUFAs는 임신 3 분기 에 대부분 모체에서 태아로 이동하여 축척이 급격하게 증가하는 시 
기로 $50 \mathrm{mg} / \mathrm{kg} / \mathrm{d}$ 이상의 DHA가 저장이 되는데 이는 총 지방산의 $1 \%$ 를 DHA로 섭취하는 양과 같다 ${ }^{64-66)}$. 태아기동안 축척된 LCFUPAs 는 출생 이후 기관의 형성 및 성숙 과정이 이루어지는 시기에 사용 되고, 단백질 생성과 신경 세포의 세분화 및 성숙, 세포 생존을 조절 하고 지질 성분의 세포 구조를 유지하며 간상 세포 광수용체의 구성 요소로 중요한 역할을 담당한다 ${ }^{65-69)}$. 특히 DHA와 arachidonic acid (AA)는 염증 반응과 면역 반응 조절에도 관여한다 ${ }^{65)}$.

미숙아는 출생 후 모체로부터 공급에 의존하던 LCPUFAs의 이동 이 갑자기 중단됨과 함께 adipose tissue의 저장량 감소를 동반한 다. 그러므로 출생 후 LCPUFAs의 공급은 전적으로 장관 또는 정맥 영양에 의존하게 된다. 모유에 LCPUFAs가 함유되었지만 미숙아의 LCPUFAs 필요량에 비해 부족한 것으로 알려져 있으며, 특히 미숙아 가 위중한 질환이 있는 경우 지방산의 대사 과정의 변화의 기전과 그 에 따른 LCPUFAs의 요구도에 대해서는 아직까지 명확하게 밝혀져 있지 않다 ${ }^{70,71)}$. 이러한 미숙아에서 LCPUFAs 부족은 기관지폐 이형 성증, 괴사성 장염, 미숙아 망막증, 패혈증 및 불량한 신경발달학적 예후와 관련되는 것으로 알려져 있다 ${ }^{72-74)}$.

뇌 발달과 관련되는 LCPUFAs의 역할은 뇌 발달과 성숙에 중요한 신호 체계를 조절하고 지질다당질(lipopolysaccharide)에 의한 뇌 손 상과 뇌 손상에 의한 후유증을 감소시키는 데 관여하는 것으로 생각 된다 ${ }^{65)}$. 미숙아의 급성 또는 만성 감염은 불량한 신경학적 예후에 영
향을 미치는 대표적인 위험 인자이며, 염증 반응에 의해서 미세아교 세포의 활성화, 산화에 의한 손상, 세포 괴사를 초래하는 것으로 생 각된다 ${ }^{75,76)}$. LCPUFAs는 염증 반응의 조절에 관여하는 것으로 알려 져 있으며, 동물 실험에서는 DHA 농도에 따라서 염증반응의 표지자 와 산화에 의한 손상이 감소하는 양상을 보였다 ${ }^{77,78)}$.

\section{Long-Chain Polyunsaturated Fatty Acids와 미숙아의 신경발달학적 예후}

Smithers 등 ${ }^{79)}$ 은 33주 미만의 미숙아를 대상으로 고용량(1\% total fatty acids)와 저용량( $0.3 \%$ total fatty acids)의 DHA를 예정일까지 보 충한 후 교정 연령 2, 4개월에 시각 유발 전위(Visual Evoked Potential, VEP)를 시행하였다. 교정 2개월에는 두 군간의 시력 차이가 보 이지 않았으나 교정 4 개월에 시행한 VEP에서는 고용량의 DHA를 보 충한 미숙아의 시력이 더 높게 확인되었다. Molloy 등 ${ }^{80)}$ 은 33주 미만 의 미숙아를 대상으로 생후 첫 한달 동안 고용량을 투여한 군과 대조 군으로 나누어 7 세에 시신경의 기능을 평가하였는데 두 군간의 차이 를 보이지 않았다.

LCPUFAs의 보충 요법과 단기 혹은 장기적인 신경발달학적 예후 와의 관련성에 대한 임상적 시도가 이루어지고 있다(Table 2). Henriksen 등 $^{81}$ 은 출생 체중 $1,500 \mathrm{~g}$ 미만의 미숙아에게 생후 1 주 이후 부 터 퇴원 전까지 DHA와 $\mathrm{AA}$ 를 보충한 후 6개월에 인지 기능을 평가하

Table 2. Clinical Trials of Long Chain Polyunsaturated Fatty Acids Supplementation in Preterm Infants

\begin{tabular}{|c|c|c|c|c|}
\hline Author/year & Population & Intervention & Outcome measures & Results \\
\hline $\begin{array}{l}\text { Markides M, et al. } \\
2009^{83)}\end{array}$ & $\begin{array}{r}<33 \text { weeks' } \\
\text { gestation }\end{array}$ & $\begin{array}{l}\text { High-DHA ( } 1 \% \text { total fatty acids) } \\
\text { vs standard DHA ( } 0.3 \% \text { total } \\
\text { fatty acids) }\end{array}$ & $\begin{array}{r}\text { BSID-II at } 18 \\
\text { months' CA }\end{array}$ & $\begin{array}{l}\text { High }(\mathrm{n}=322) \text { vs. Standard }(\mathrm{n}=335) \\
\text { MDI: } 94.9 \pm 14.5 \text { vs. } 93.0 \pm 17.3(P=0.26) \\
\text { MDI of girls: } 99.1 \pm 13.9 \text { vs. } 94.4 \pm 17.5(P=0.03) \\
\text { PDI: } 93.1 \pm 16.1 \text { vs. } 92.1 \pm 16.3(P=0.51)\end{array}$ \\
\hline $\begin{array}{l}\text { Westerberg AC, et al. } \\
2011^{82)}\end{array}$ & $<1,500 \mathrm{~g}$ & $\begin{array}{l}32 \text { mg DHA and } 31 \text { mg AA per } \\
10 \text { mL milk from } 1 \text { week after } \\
\text { birth until discharge ( } 9 \text { weeks } \\
\text { on average) }\end{array}$ & $\begin{array}{l}\text { BSID-II (MDI) at } \\
20 \text { months }\end{array}$ & $\begin{array}{l}\text { LCPUFA ( } \mathrm{n}=40) \text { vs. control }(\mathrm{n}=42) \\
\text { MDI: } 83.5 \pm 10.5 \text { vs. } 82.9 \pm 13.3(P=0.83)\end{array}$ \\
\hline $\begin{array}{l}\text { Smithers LG, et al. } \\
2010^{84)}\end{array}$ & $\begin{array}{r}<33 \text { weeks' } \\
\text { gestation }\end{array}$ & $\begin{array}{l}\text { High-DHA ( } 1 \% \text { total fatty acids) } \\
\text { vs. standard DHA ( } 0.3 \% \text { total } \\
\text { fatty acids) }\end{array}$ & $\begin{array}{l}\text { MCDI at } 26 \\
\text { months' CA }\end{array}$ & $\begin{array}{l}\text { High }(\mathrm{n}=60) \text { vs. Standard }(\mathrm{n}=67) \\
\text { Vocabulary production: } 308 \pm 179 \text { vs. } 316 \pm 192(P=0.8) \\
\text { Sentence complexity: } 7 \pm 13 \text { vs. } 7 \pm 13(P=0.9)\end{array}$ \\
\hline $\begin{array}{l}\text { Collins CT, et al. } \\
2015^{85)}\end{array}$ & $\begin{array}{r}<33 \text { weeks' } \\
\text { gestation }\end{array}$ & $\begin{array}{l}\text { High-DHA ( } 1 \% \text { total fatty acids) } \\
\text { vs. standard DHA ( } 0.3 \% \text { total } \\
\text { fatty acids) }\end{array}$ & $\begin{array}{l}\text { WASI at } 7 \text { years' } \\
\text { CA }\end{array}$ & $\begin{array}{l}\text { High ( } \mathrm{n}=291) \text { vs. Standard }(\mathrm{n}=313) \\
\text { Full scale IQ: } 98.3 \pm 14.0 \text { vs. } 98.5 \pm 14.9(P=0.79) \\
\text { Verbal IQ: } 98.0 \pm 14.2 \text { vs. } 98.8 \pm 15.8(P=0.52) \\
\text { Performance IQ: } 98.5 \pm 14.2 \text { vs. } 98.8 \pm 15.8(P=0.99)\end{array}$ \\
\hline $\begin{array}{l}\text { Almaas AN, et al. } \\
2015^{86)}\end{array}$ & $<1,500 \mathrm{~g}$ & $\begin{array}{l}32 \text { mg DHA and } 31 \text { mg AA per } \\
10 \text { mL milk from } 1 \text { week after } \\
\text { birth until discharge ( } 9 \text { weeks } \\
\text { on average) }\end{array}$ & WASI at 8 years old & $\begin{array}{l}\text { LCPUFA ( } \mathrm{n}=45) \text { vs. } \operatorname{control}(\mathrm{n}=53) \\
\text { Full scale IQ: } 92.7 \pm 8.8 \text { vs. } 93.9 \pm 10.0(P=0.73) \\
\text { Verbal IQ: } 88.8 \pm 10.3 \text { vs. } 90.3 \pm 12.5(P=0.73) \\
\text { Performance IQ: } 95.0 \pm 12.6 \text { vs. } 95.9 \pm 14.4(P=0.98)\end{array}$ \\
\hline
\end{tabular}

Data are presented as mean \pm SD.

Abbreviations: DHA, docosahexaenoic acid; AA, arachidonic acid; BSID, Bayley scales of infant development; LCPUFA, long-chain polyunsaturated fatty acid; MDI, mental development index; WASI, Wechsler abbreviated scale for intelligence; IQ, intelligence quotient; CA, corrected age; MCDI, MacArthur communicative development inventory. 
였는데 DHA와 $\mathrm{AA}$ 를 보충하지 않은 미숙아와 비교하여 기억력과 문 제 해결 능력이 높았다. 앞선 연구의 미숙아를 대상으로 생후 20개월 에 인지 기능을 평가하였으며 MDI (BSID-II)는 두 군간의 차이를 보 이지 않았으나 혈중 $\mathrm{DHA}$ 농도는 집중력과 $\mathrm{MDI}$ 점수와 양의 상관 관 계를 보였다 ${ }^{82)}$. Makrides 등 ${ }^{83)}$ 은 33주 미만의 미숙아를 대상으로 생 후 2-3일에서 만삭 연령까지 고용량(1\% total fatty acids)의 DHA를 보충하였다. 대조군( $0.3 \%$ total fatty acids)과 비교하여 교정 연령 18 개월에 시행한 BSID-II에서 MDI와 PDI의 차이를 보이지 않았으나 성별을 나누어 비교하였을 때, 여아에서는 MDI가 고용량의 DHA를 보충한 미숙아에서 높았다. 또한, 고용량의 DHA를 보충한 미숙아에 서 발달 지연의 빈도가 낮았다. 교정 연령 26개월에 시행한 언어 능 력과 행동 장애의 평가에서는 두 군간의 차이가 없었다 ${ }^{84}$.

앞선 연구들의 미숙아를 대상으로 LCPUFAs, 특히 DHA의 생후 초 기 보충이 학령기 전후의 신경발달학적 예후에 미치는 연구가 이루 어졌다. Collins 등 ${ }^{85)}$ 은 33주 미만의 미숙아를 대상으로 생후 2-3일 에서 만삭 연령까지 고용량( $1 \%$ total fatty acids)의 DHA를 공급하였 고 7세에 Wechsler Abbreviated Scale of Intelligence (WASI)를 시행 하였다. 고용량의 DHA를 보충한 미숙아는 대조군( $0.3 \%$ total fatty acids)와 비교하여 IQ를 포함하여 언어 능력, 기억력, 학습 능력, 행 동 장애의 평가에서도 차이가 없었다. 출생 체중 $1,500 \mathrm{~g}$ 미만의 미 숙아에서 출생 후 평균 9주간 고용량의 DHA (0.86\%)와 AA (0.91\%) 를 공급하고 8세에 WASI와, 뇌 MRI 및 DTI를 시행하였다 ${ }^{86,87)}$. WASI 로 평가한 인지 기능, 뇌 MRI에서 뇌 용적과 표면적, DTI에서 뇌백 질의 미세 구조를 비교하였을 때, 대조군과 차이를 보이지 않았다. Isaacs 등 ${ }^{88}$ 은 35 주 미만, 출생 체중 $2,000 \mathrm{~g}$ 미만의 미숙아가 9개월간 $0.5 \% \mathrm{DHA}$ 를 함유한 분유를 수유한 후 10 세에 WASI를 시행하였다. 모유 수유를 하지 않은 미숙아에서는 DHA가 함유된 분유를 수유한 미숙아에서 전체 IQ, 어휘 IQ 및 기억 능력이 높았으나 모유 수유를 한 그룹 내 비교에서는 차이가 없었다.

\section{결론}

미숙아의 신경 보호와 신경 발달을 향상시키기 위한 Epo의 적용 과 LCPUFA 투여를 포함한 영양학적 중재에 관한 임상 연구가 활발 히 진행되고 있다. 안전성 문제를 비롯하여 미숙아의 신경발달학적 예후와 긍정적인 관련성에 대해서 다양한 결론들이 보고되고 있다. 현재까지 미숙아에서 Epo와 LCPUFA의 적절한 용량, 시작 시점, 투 여 시기와 기간, 투여 방법, 효과의 최적화를 위한 적용 대상군과 병 행 치료 방법에 대한 명확한 기준이 정해지지 않은 상태로 향후 이에 대한 지속적인 연구가 필요하다. 또한 미숙아의 장기 추적 관찰을 통 해서 신경 발달 향상과의 관련성과 함께 안전성에 대한 평가도 필요 하다.

\section{REFERENCES}

1) Juul SE, Pet GC. Erythropoietin and neonatal neuroprotection. Clin Perinatol 2015;42:469-81.

2) McAdams RM JS. Cerebral Palsy: prevalence, predictability, and parental counseling. NeoReviews 2011;12:564-74.

3) Wood NS, Marlow N, Costeloe K, Gibson AT, Wilkinson AR. Neurologic and developmental disability after extremely preterm birth. EPICure Study Group. N Engl J Med 2000;343:37884.

4) Marlow N, Wolke D, Bracewell MA, Samara M. Neurologic and developmental disability at six years of age after extremely preterm birth. N Engl J Med 2005;352:9-19.

5) Rajagopalan V, Scott J, Habas PA, Kim K, Corbett-Detig J, Rousseau $\mathrm{F}$, et al. Local tissue growth patterns underlying normal fetal human brain gyrification quantified in utero. J Neurosci 2011;31:2878-87.

6) Lodygensky GA, Vasung L, Sizonenko SV, Huppi PS. Neuroimaging of cortical development and brain connectivity in human newborns and animal models. J Anat 2010;217:418-28.

7) McQuillen PS, Ferriero DM. Selective vulnerability in the developing central nervous system. Pediatr Neurol 2004;30:22735.

8) Volpe JJ. The encephalopathy of prematurity--brain injury and impaired brain development inextricably intertwined. Semin Pediatr Neurol 2009;16:167-78.

9) Back SA. Cerebral white and gray matter injury in newborns: new insights into pathophysiology and management. Clin Perinatol 2014;41:1-24.

10) Kidokoro H, Neil JJ, Inder TE. New MR imaging assessment tool to define brain abnormalities in very preterm infants at term. AJNR Am J Neuroradiol 2013;34:2208-14.

11) Juul SE, Mayock DE, Comstock BA, Heagerty PJ. Neuroprotective potential of erythropoietin in neonates; design of a randomized trial. Matern Health Neonatol Perinatol 2015;1:27.

12) Bartha AI, Foster-Barber A, Miller SP, Vigneron DB, Glidden DV, Barkovich AJ, et al. Neonatal encephalopathy: association of cytokines with MR spectroscopy and outcome. Pediatr Res 2004;56:960-6.

13) Strunk T, Inder T, Wang $X$, Burgner $D$, Mallard C, Levy $O$. Infection-induced inflammation and cerebral injury in preterm infants. Lancet Infect Dis 2014;14:751-62.

14) Jakuskiene R, Vollmer B, Saferis V, Daugeliene D. Neonatal outcomes of very preterm infants admitted to a tertiary center in Lithuania between the years 2003 and 2005. Eur J Pediatr 2011;170:1293-303.

15) Nagy Z, Ashburner J, Andersson J, Jbabdi S, Draganski B, Skare $\mathrm{S}$, et al. Structural correlates of preterm birth in the adolescent brain. Pediatrics 2009;124:964-72. 
16) Lubsen J, Vohr B, Myers E, Hampson M, Lacadie C, Schneider $\mathrm{KC}$, et al. Microstructural and functional connectivity in the developing preterm brain. Semin Perinatol 2011;35:34-43.

17) Masuda S, Nagao M, Sasaki R. Erythropoietic, neurotrophic, and angiogenic functions of erythropoietin and regulation of erythropoietin production. Int J Hematol 1999;70:1-6.

18) Sugawa M, Sakurai $Y$, Ishikawa-Ieda $Y$, Suzuki H, Asou H. Effects of erythropoietin on glial cell development; oligodendrocyte maturation and astrocyte proliferation. Neurosci Res 2002;44: 391-403.

19) Rangarajan V, Juul SE. Erythropoietin: emerging role of erythropoietin in neonatal neuroprotection. Pediatr Neurol 2014;51: 481-8.

20) Villa P, Bigini P, Mennini T, Agnello D, Laragione T, Cagnotto A, et al. Erythropoietin selectively attenuates cytokine production and inflammation in cerebral ischemia by targeting neuronal apoptosis. J Exp Med 2003;198:971-5.

21) Xiong Y, Mahmood A, Zhang Y, Meng Y, Zhang ZG, Qu C, et al. Effects of posttraumatic carbamylated erythropoietin therapy on reducing lesion volume and hippocampal cell loss, enhancing angiogenesis and neurogenesis, and improving functional outcome in rats following traumatic brain injury. J Neurosurg 2011;114:549-59.

22) Juul SE, Ferriero DM. Pharmacologic neuroprotective strategies in neonatal brain injury. Clin Perinatol 2014;41:119-31.

23) Iwai M, Stetler RA, Xing J, Hu X, Gao Y, Zhang W, et al. Enhanced oligodendrogenesis and recovery of neurological function by erythropoietin after neonatal hypoxic/ischemic brain injury. Stroke 2010;41:1032-7.

24) Neubauer AP, Voss W, Wachtendorf M, Jungmann T. Erythropoietin improves neurodevelopmental outcome of extremely preterm infants. Ann Neurol 2010;67:657-66.

25) van de Looij Y, Chatagner A, Quairiaux C, Gruetter R, Huppi PS, Sizonenko SV. Multi-modal assessment of long-term erythropoietin treatment after neonatal hypoxic-ischemic injury in rat brain. PLoS One 2014;9:e95643.

26) Juul SE, McPherson RJ, Bauer LA, Ledbetter KJ, Gleason CA, Mayock DE. A phase I/II trial of high-dose erythropoietin in extremely low birth weight infants: pharmacokinetics and safety. Pediatrics 2008;122:383-91.

27) Fauchere JC, Dame C, Vonthein R, Koller B, Arri S, Wolf M, et al. An approach to using recombinant erythropoietin for neuroprotection in very preterm infants. Pediatrics 2008;122:375-82.

28) Fauchere JC, Koller BM, Tschopp A, Dame C, Ruegger C, Bucher HU, et al. Safety of early high-dose recombinant erythropoietin for neuroprotection in very preterm infants. J Pediatr 2015;167:52-7.

29) Bierer R, Peceny MC, Hartenberger CH, Ohls RK. Erythropoietin concentrations and neurodevelopmental outcome in preterm infants. Pediatrics 2006;118:635-40.

30) Song J, Sun H, Xu F, Kang W, Gao L, Guo J, et al. Recombinant human erythropoietin improves neurological outcomes in very preterm infants. Ann Neurol 2016;80:24-34.

31) Natalucci G, Latal B, Koller B, Ruegger C, Sick B, Held L, et al. Effect of early prophylactic high-dose recombinant human erythropoietin in very preterm infants on neurodevelopmental outcome at 2 years: A randomized clinical trial. JAMA 2016;315: 2079-85.

32) Ohls RK, Cannon DC, Phillips J, Caprihan A, Patel S, Winter $\mathrm{S}$, et al. Preschool assessment of preterm infants treated with darbepoetin and erythropoietin. Pediatrics 2016;137: e20153859.

33) Lowe JR, Rieger RE, Moss NC, Yeo RA, Winter S, Patel S, et al. Impact of erythropoiesis-stimulating agents on behavioral measures in children born preterm. J Pediatr 2017;184:75-80.

34) Leuchter RH, Gui L, Poncet A, Hagmann C, Lodygensky GA, Martin E, et al. Association between early administration of high-dose erythropoietin in preterm infants and brain MRI abnormality at term-equivalent age. JAMA 2014;312:817-24.

35) Woodward LJ, Anderson PJ, Austin NC, Howard K, Inder TE. Neonatal MRI to predict neurodevelopmental outcomes in preterm infants. N Engl J Med 2006;355:685-94.

36) O'Gorman RL, Bucher HU, Held U, Koller BM, Huppi PS, Hagmann CF. Tract-based spatial statistics to assess the neuroprotective effect of early erythropoietin on white matter development in preterm infants. Brain 2015;138:388-97.

37) Ruegger CM, Hagmann CF, Buhrer C, Held L, Bucher HU, Wellmann S, et al. Erythropoietin for the repair of cerebral injury in very preterm infants (EpoRepair). Neonatology 2015;108:198204.

38) Wachs TD, Georgieff M, Cusick S, McEwen BS. Issues in the timing of integrated early interventions: contributions from nutrition, neuroscience, and psychological research. Ann N Y Acad Sci 2014;1308:89-106.

39) Cusick SE, Georgieff MK. The role of nutrition in brain development:vthe golden opportunity of the "first 1000 days". J Pediatr 2016;175:16-21.

40) Fox SE, Levitt P, Nelson CA, 3rd. How the timing and quality of early experiences influence the development of brain architecture. Child Dev 2010;81:28-40.

41) Schneider N, Garcia-Rodenas CL. Early nutritional interventions for brain and cognitive development in preterm infants: a review of the literature. Nutrients 2017;9:187.

42) dit Trolli SE, Kermorvant-Duchemin E, Huon C, BremondGignac D, Lapillonne A. Early lipid supply and neurological development at one year in very low birth weight (VLBW) preterm infants. Early Hum Dev 2012;88:S25-9.

43) Franz AR, Pohlandt F, Bode H, Mihatsch WA, Sander S, Kron 
$\mathrm{M}$, et al. Intrauterine, early neonatal, and postdischarge growth and neurodevelopmental outcome at 5.4 years in extremely preterm infants after intensive neonatal nutritional support. Pediatrics 2009;123:101-9.

44) Isaacs EB, Morley R, Lucas A. Early diet and general cognitive outcome at adolescence in children born at or below 30 weeks gestation. J Pediatr 2009;155:229-34.

45) Biasini A, Marvulli L, Neri E, China M, Stella M, Monti F. Growth and neurological outcome in ELBW preterms fed with human milk and extra-protein supplementation as routine practice: do we need further evidence? J Matern Fetal Neonatal Med 2012; 25:S72-4.

46) Tan M, Abernethy L, Cooke R. Improving head growth in preterm infants--a randomised controlled trial II: MRI and developmental outcomes in the first year. Arch Dis Child Fetal Neonatal Ed 2008;93:342-6.

47) Stephens BE, Walden RV, Gargus RA, Tucker R, McKinley L, Mance M, et al. First-week protein and energy intakes are associated with 18-month developmental outcomes in extremely low birth weight infants. Pediatrics 2009;123:1337-43.

48) Ohnishi S, Ichiba H, Tanaka $Y$, Harada S, Matsumura H, Kan A, et al. Early and intensive nutritional strategy combining parenteral and enteral feeding promotes neurodevelopment and growth at 18months of corrected age and 3 years of age in extremely low birth weight infants. Early Hum Dev 2016;100:3541.

49) Blanco CL, Gong AK, Schoolfield J, Green BK, Daniels W, Liechty EA, et al. Impact of early and high amino acid supplementation on ELBW infants at 2 years. J Pediatr Gastroenterol Nutr 2012;54:601-7.

50) Beauport L, Schneider J, Faouzi M, Hagmann P, Huppi PS, Tolsa JF, et al. Impact of early nutritional intake on preterm brain: a magnetic resonance imaging study. J Pediatr 2017;181:29-36.

51) Strommen K, Blakstad EW, Moltu SJ, Almaas AN, Westerberg AC, Amlien IK, et al. Enhanced nutrient supply to very low birth weight infants is associated with improved white matter maturation and head growth. Neonatology 2015;107:68-75.

52) Fenton TR, Premji SS, Al-Wassia H, Sauve RS. Higher versus lower protein intake in formula-fed low birth weight infants. Cochrane Database Syst Rev 2014;4:Cd003959.doi: 10.1002/14651858.CD003959.pub3.

53) Lechner BE, Vohr BR. Neurodevelopmental outcomes of preterm infants fed human milk: a systematic review. Clin Perinatol 2017;44:69-83.

54) Belfort MB, Ehrenkranz RA. Neurodevelopmental outcomes and nutritional strategies in very low birth weight infants. Semin Fetal Neonatal Med 2017;22:42-8.

55) Koo W, TankS, Martin S, Shi R. Human milk and neurodevelopment in children with very low birth weight: a systematic re- view. Nutr J 2014;13:94.

56) Zivkovic AM, German JB, Lebrilla CB, Mills DA. Human milk glycobiome and its impact on the infant gastrointestinal microbiota. Proc Natl Acad Sci U S A 2011;108:S4653-8.

57) Hintz SR, Kendrick DE, Stoll BJ, Vohr BR, Fanaroff AA, Donovan EF, et al. Neurodevelopmental and growth outcomes of extremely low birth weight infants after necrotizing enterocolitis. Pediatrics 2005;115:696-703.

58) Vohr BR, Poindexter BB, Dusick AM, McKinley LT, Wright LL, Langer JC, et al. Beneficial effects of breast milk in the neonatal intensive care unit on the developmental outcome of extremely low birth weight infants at 18 months of age. Pediatrics 2006; 118:115-23.

59) Vohr BR, Poindexter BB, Dusick AM, McKinley LT, Higgins RD, Langer JC, et al. Persistent beneficial effects of breast milk ingested in the neonatal intensive care unit on outcomes of extremely low birth weight infants at 30 months of age. Pediatrics 2007;120:953-9.

60) Tanaka K, Kon N, Ohkawa N, Yoshikawa N, Shimizu T. Does breastfeeding in the neonatal period influence the cognitive function of very-low-birth-weight infants at 5 years of age? Brain Dev 2009;31:288-93.

61) Isaacs EB, Fischl BR, Quinn BT, Chong WK, Gadian DG, Lucas A. Impact of breast milk on intelligence quotient, brain size, and white matter development. Pediatr Res 2010;67:357-62.

62) Deoni SC, Dean DC, 3rd, Piryatinsky I, O'Muircheartaigh J, Waskiewicz N, Lehman K, et al. Breastfeeding and early white matter development: a cross-sectional study. Neuroimage 2013;82:77-86.

63) Belfort MB, Anderson PJ, Nowak VA, Lee KJ, Molesworth C, Thompson DK, et al. Breast milk feeding, brain development, and neurocognitive outcomes: a 7-year longitudinal study in infants born at less than 30 weeks' gestation. J Pediatr 2016; 177:133-9.

64) Clandinin MT, Chappell JE, Leong S, Heim T, Swyer PR, Chance GW. Intrauterine fatty acid accretion rates in human brain: implications for fatty acid requirements. Early Hum Dev 1980; 4:121-9.

65) Martin CR. Fatty acid requirements in preterm infants and their role in health and disease. Clin Perinatol 2014;41:363-82.

66) Makrides M, Uauy R. LCPUFAs as conditionally essential nutrients for very low birth weight and low birth weight infants: metabolic, functional, and clinical outcomes-how much is enough? Clin Perinatol 2014;41:451-61.

67) Larque E, Demmelmair H, Gil-Sanchez A, Prieto-Sanchez MT, Blanco JE, Pagan A, et al. Placental transfer of fatty acids and fetal implications. Am J Clin Nutr 2011;94:S1908-13.

68) Haggarty P. Fatty acid supply to the human fetus. Ann Rev Nutr 2010;30:237-55. 
69) Lauritzen L, Hansen HS, Jorgensen MH, Michaelsen KF. The essentiality of long chain n-3 fatty acids in relation to development and function of the brain and retina. Prog Lipid Res 2001; 40:1-94.

70) Larque E, Demmelmair H, Koletzko B. Perinatal supply and metabolism of long-chain polyunsaturated fatty acids: importance for the early development of the nervous system. Ann NY Acad Sci 2002;967:299-310.

71) Carnielli VP, Wattimena DJ, Luijendijk IH, Boerlage A, Degenhart HJ, Sauer PJ. The very low birth weight premature infant is capable of synthesizing arachidonic and docosahexaenoic acids from linoleic and linolenic acids. Pediatr Res 1996;40:16974.

72) Martin CR, Dasilva DA, Cluette-Brown JE, Dimonda C, Hamill A, Bhutta AQ, et al. Decreased postnatal docosahexaenoic and arachidonic acid blood levels in premature infants are associat ed with neonatal morbidities. J Pediatr 2011;159:743-9.

73) Lu J, Jilling T, Li D, Caplan MS. Polyunsaturated fatty acid supplementation alters proinflammatory gene expression and reduces the incidence of necrotizing enterocolitis in a neonatal rat model. Pediatr Res 2007;61:427-32.

74) Pawlik D, Lauterbach R, Walczak M, Hurkala J, Sherman MP. Fish-oil fat emulsion supplementation reduces the risk of re tinopathy in very low birth weight infants: a prospective, randomized study. JPEN J Parenter Enteral Nutr 2014;38:711-6.

75) Stoll BJ, Hansen NI, Adams-Chapman I, Fanaroff AA, Hintz SR, Vohr B, et al. Neurodevelopmental and growth impairment among extremely low-birth-weight infants with neonatal infection. JAMA 2004;292:2357-65.

76) Adams-Chapman I, Bann CM, Das A, Goldberg RN, Stoll BJ, Walsh MC, et al. Neurodevelopmental outcome of extremely low birth weight infants with Candida infection. J Pediatr 2013; 163:961-7.

77) Williams JJ, Mayurasakorn K, Vannucci SJ, Mastropietro C, Bazan NG, Ten VS, et al. N-3 fatty acid rich triglyceride emulsions are neuroprotective after cerebral hypoxic-ischemic injury in neonatal mice. PLoS One 2013;8:e56233.

78) Antonietta Ajmone-Cat M, Lavinia Salvatori M, De Simone R, Mancini M, Biagioni S, Bernardo A, et al. Docosahexaenoic acid modulates inflammatory and antineurogenic functions of activated microglial cells. J Neurosci Res 2012;90:575-87.

79) Smithers LG, Gibson RA, McPhee A, Makrides M. Higher dose of docosahexaenoic acid in the neonatal period improves visual acuity of preterm infants: results of a randomized controlled trial. Am J Clin Nutr 2008;88:1049-56.

80) Molloy CS, Stokes S, Makrides M, Collins CT, Anderson PJ. Longterm effect of high-dose supplementation with DHA on visual function at school age in children born at $<33 \mathrm{wk}$ gestational age: results from a follow-up of a randomized controlled trial. Am J Clin Nutr 2016;103:268-75.

81) Henriksen C, Haugholt K, Lindgren M, Aurvag AK, Ronnestad A, Gronn M, et al. Improved cognitive development among preterm infants attributable to early supplementation of human milk with docosahexaenoic acid and arachidonic acid. Pediatrics 2008;121:1137-45.

82) Westerberg AC, Schei R, Henriksen C, Smith L, Veierod MB, Drevon CA, et al. Attention among very low birth weight infants following early supplementation with docosahexaenoic and arachidonic acid. Acta Paediatr 2011;100:47-52.

83) Makrides M, Gibson RA, McPhee AJ, Collins CT, Davis PG, Doyle LW, et al. Neurodevelopmental outcomes of preterm infants fed high-dose docosahexaenoic acid: a randomized controlled trial. JAMA 2009;301:175-82.

84) Smithers LG, Collins CT, Simmonds LA, Gibson RA, McPhee A, Makrides M. Feeding preterm infants milk with a higher dose of docosahexaenoic acid than that used in current practice does not influence language or behavior in early childhood: a followup study of a randomized controlled trial. Am J Clin Nutr 2010; 91:628-34.

85) Collins CT, Gibson RA, Anderson PJ, McPhee AJ, Sullivan TR, Gould JF, et al. Neurodevelopmental outcomes at 7 years' corrected age in preterm infants who were fed high-dose docosahexaenoic acid to term equivalent: a follow-up of a randomised controlled trial. BMJ Open 2015;5:e007314.doi: 10.1136/ bmjopen-2010-007314.

86) Almaas AN, Tamnes CK, Nakstad B, Henriksen C, Walhovd $\mathrm{KB}$, Fjell AM, et al. Long-chain polyunsaturated fatty acids and cognition in VLBW infants at 8 years: an RCT. Pediatrics 2015; 135:972-80.

87) Almaas AN, Tamnes CK, Nakstad B, Henriksen C, Grydeland $\mathrm{H}$, Walhovd KB, et al. Diffusion tensor imaging and behavior in premature infants at 8 years of age, a randomized controlled trial with long-chain polyunsaturated fatty acids. Early Hum Dev 2016;95:41-6.

88) Isaacs EB, Ross S, Kennedy K, Weaver LT, Lucas A, Fewtrell MS. 10 -year cognition in preterms after random assignment to fatty acid supplementation in infancy. Pediatrics 2011;128:890-8. 